\title{
A numerical evaluation of adaptive on-off cooling strategies for energy savings during long-term storage of apples
}

\author{
W. Gruyters ${ }^{a}$, P. Verboven ${ }^{a}$, M. Delele ${ }^{a}$, S.G. Gwanpuaa, ${ }^{a, c}$ A. Schenk ${ }^{b}$, B. Nicolaï ${ }^{a, b, *}$ \\ ${ }^{\text {a }}$ Postharvest group, BIOSYST-MeBioS, KU Leuven, Leuven, B-3001, Belgium \\ ${ }^{\mathrm{b}}$ Flanders Centre of Postharvest Technology, Leuven, B-3001, Belgium \\ ${ }^{\mathrm{c}}$ Centre for Postharvest and Refrigeration Research, Massey University, Palmerston North, New Zealand \\ *Corresponding author. Email: bart.nicolai@kuleuven.be
}

\begin{abstract}
The main energy costs of long-term apple storage are associated with cooling. Reducing these costs without compromising product quality may be possible with minor room temperature increases. This paper presents a transient CFD model to evaluate automatic on-off cooling control based on different temperature differentials $\left(0.4,0.5\right.$ and $0.7{ }^{\circ} \mathrm{C}$ around a setpoint). Effects on temperature uniformity, quality changes and energy consumption during long-term storage of apples were calculated. A model for apple firmness change kinetics was coupled to the CFD model and applied to calculate changes in quality uniformity in a coolstore affected by spatiotemporal fluctuations in temperature. Large temperature fluctuations were observed near the outer edges of the stack and were more pronounced with a higher cooling differential. Using a small cooling differential around the setpoint temperature showed a better overall performance in terms of energy consumption and final product quality.
\end{abstract}

KEYWORDS: Energy saving; apple storage; computational fluid dynamics; porous medium; FRISBEE tool

\section{Nomenclature}

$\begin{array}{ll}A & \text { area }\left[\mathrm{m}^{2}\right] \\ \text { CA } & \text { controlled atmosphere } \\ \text { CFD } & \text { computational fluid dynamics } \\ C_{p} & \text { specific heat capacity }\left[\mathrm{J} \mathrm{kg}^{-1} \mathrm{~K}^{-1}\right] \\ h & \text { heat transfer coefficient }\left[\mathrm{W} \mathrm{m} \mathrm{K}^{-1}\right] \\ k & \text { thermal conductivity }\left[\mathrm{W} \mathrm{m}^{-1} \mathrm{~K}^{-1}\right] \\ m & \text { mass }[\mathrm{kg}] \\ q_{a} & \text { volume airflow rate }\left[\mathrm{m}^{-3} \mathrm{~s}^{-1}\right] \\ \mathrm{SST} & \text { shear stress transport } \\ T & \text { temperature }[\mathrm{K}]\end{array}$

Greek symbols $\rho$ density $\left[\mathrm{kg} \mathrm{m}^{-3}\right]$

Subscript

a

c air evaporator tubes inside the cooling unit 
inlet

\section{Introduction}

After harvest, pomefruit are often stored at low temperature in combination with controlled atmosphere $(\mathrm{CA})$ conditions (reduced $\mathrm{O}_{2}$ and increased $\mathrm{CO}_{2}$ concentrations) to extend their storage life whilst preserving a high quality and reducing postharvest losses (Thompson et al., 2008). The respiration rate of pomefruit and, thus, their process of senescence and deterioration is tightly linked to temperature (Prusky, 2011). It is, therefore, essential to store the produce within a narrow range of low temperatures during the total length of the storage period which can last up to ten months after harvest, depending on the cultivar and CA conditions (ASHRAE, 2010). For apples, the optimal storage temperature is between $0{ }^{\circ} \mathrm{C}$ and $3{ }^{\circ} \mathrm{C}$ (Rees et al., 2012). In combination with 1-MCP, a gaseous suppressor of ethylene action and thus fruit ripening, it is possible to store apples at even higher temperatures without a noticeable effect on the quality (McCormick et al. 2010). Gwanpua et al. (2013) developed and validated a stochastic kinetic model of the firmness breakdown of apples as a function of CA conditions, storage time and temperature. This model was used to assess the effect of three different storage temperatures $\left(1{ }^{\circ} \mathrm{C}, 2{ }^{\circ} \mathrm{C}, 3{ }^{\circ} \mathrm{C}\right)$ during long-term storage on apple firmness and subsequently on the consumer acceptance. From the simulations it appeared that the final firmness of apples after four months storage at $1{ }^{\circ} \mathrm{C}$ or $3{ }^{\circ} \mathrm{C}$ was comparable and not below the minimum threshold for export. This seemed to provide a clear benefit for a flexible cold chain management to reduce energy costs by storing fruit at higher temperatures. The fruit tolerance to temperature fluctuations during storage, however, has rarely been considered. East et al. (2013) devised an experiment to analyse quality changes by changing temperature setpoints from 0.5 to $4.0{ }^{\circ} \mathrm{C}$ with increasing fluctuations up to $2.0{ }^{\circ} \mathrm{C}$ during $\mathrm{CA}$ storage of apples in experimental containers. Differences in quality were also found negligible for different apple cultivars after several months of storage. The effect of differences in fluctuations around the optimal temperature setpoint was not considered.

Growers, cooperatives and wholesalers are looking for alternative cooling strategies to reduce the high refrigeration costs which can contribute up to $60 \%$ to the total variable costs (Kart and Demircan, 2014). By using a lumped-model analysis, East et al. (2013) showed that avoiding cooling during peak price hours and concentrating cooling during off-peak hours may result in a $40 \%$ cost reduction, but does not save on actual energy use while allowing more temperature fluctuations. By reducing the working time of the fans with an on/off cycling regime, Ambaw et al. (2016) found that there was a significant decrease in heat load, showing promising possibilities for energy reduction compared to 
continuous cooling without compromising the product temperatures. However, the impact of the temperature fluctuations on the quality of the apples was not investigated.

Dedicated temperature management strategies should prevent chilling injury and maintain quality. In general, a temperature differential range around the optimal storage temperature (i.e., the setpoint temperature of the coolstore) is allowed but the permissible limits around the optimal storage temperature is not yet know. The value of the differential may also affect energy consumption, by changing the number and duration of cooling actions and intermediate non-cooling periods. Yet, one should also consider the effects on temperature and product quality uniformity in the storage room.

Developing numerical models based on computational fluid dynamics (CFD) is a cost-effective alternative to study cooling processes both on a small and large scale (Ambaw et al., 2013a; Defraeye et al., 2015). Furthermore, by solving the different transport equations of a fluid (conservation of energy, mass and momentum) with the help of numerical techniques, it is possible to study the possible interactions of a fluid and its environment in a high spatial as well as temporal resolution (Blazek, 2015; Versteeg and Malalasekera, 2007). With CFD, one has the potential to gain a more fundamental insight into the cooling process and obtain all the relevant information that is otherwise very difficult to obtain experimentally and this in a fast manner.

The objective of this work was to study the effect of changing the temperature differential range for cooled storage of apple (Malus $\times$ domestica Borkh, cv. 'Jonagold') at an optimal temperature of 0.95 ${ }^{\circ} \mathrm{C}$ within a commercial CA coolstore. Different scenarios were evaluated with a validated porous medium CFD model. To properly take into account the heat transfer dynamics, the CFD model was extended with an evaporator and controller model to implement the differential temperature strategies as well as extended with a quality change kinetics model. The spatiotemporal temperature distributions at various positions within the fruit bin stack, and the corresponding evolution of the product quality were computed together with the energy use during long-term storage in each storage scenario.

\section{Material and methods}

\subsection{Fruit bins and commercial coolstore facility}

The configuration of the commercial coolstore is based on an existing coolstore (Belgische Fruitveiling, Sint-Truiden, Belgium; Ambaw et al., 2013b). The $434 \mathrm{~m}^{3}$ commercial coolstore with a depth of $9.73 \mathrm{~m}$, a width of $6.03 \mathrm{~m}$ and a height of $7.40 \mathrm{~m}$ was loaded with 208 wooden fruit bins of dimensions $1.20 \mathrm{~m} \times 1.20 \mathrm{~m} \times 0.74 \mathrm{~m}$, each assumed holding $380 \mathrm{~kg}$ of apples (Malus $\times$ domestica Borkh, cv. 'Jonagold'; see Figure 1). The stacking pattern of the wooden fruit bins consisted of four columns (15 cm apart), five rows with eight layers of bins and two rows in front of the door with six 
layers (10 cm apart in height and depth direction). The total open area of a typical wooden fruit bin (i.e., the gap between the wooden planks) is $6 \%$ and $5 \%$ for the bottom and vertical faces, respectively. The walls and ceiling of the coolstore were made out of polystyrene sandwich panels with a thermal conductivity of $0.022 \mathrm{~W}\left(\mathrm{~m}^{\circ} \mathrm{C}\right)^{-1}$ (ASHRAE, 2006). The floor consisted of insulated concrete with a similar thermal conductivity. The coolstore was equipped with a cooling unit positioned near the opposite wall to the door side, above the fruit bins with five fans of $0.8 \mathrm{~kW}$ each in a 'blow through' fan coil configuration. The airflow exchange rate of the cooling unit was $40,500 \mathrm{~m}^{3} \mathrm{~h}^{-1}$ and had a refrigeration capacity of $20 \mathrm{~kW}$. A typical on-off cooling cycle of a common CA coolstore is controlled by the reading of a temperature sensor (usually a pt1000-type temperature sensor) positioned at the wall under the cooling unit in the returning airflow after passing through the stack of bins (see Figure 2). This type of temperature sensor measures the temperature up to $0.01{ }^{\circ} \mathrm{C}$ resolution.

\subsection{Porous medium CFD model formulation}

Based on the previous work of Ambaw et al. $(2013 b$; 2016) that described the governing equations and a validation with both a small-scale experiment and discrete element-CFD model, a porous medium CFD model of the apple coolstore was generated. The computational domain is shown in Figure 2. The computational cost of this model was reduced considerably by modelling all the stacked fruit bins as one large porous medium that consists of both a solid and fluid phase (i.e., the apple fruit in the wooden bins and the cooling air, respectively) with a constant volume fraction (0.565) in time and space (Hoang et al., 2015; Liu and Masliyah, 2005) while the free air, enclosed by the boundaries of the room (floor, walls, ceiling and door) was modelled as a fluid domain. Due to the symmetric layout of the coolstore, only half of the coolstore was modelled. A conservative flux interface boundary for the conservation of momentum and scalar equations was selected at the interfaces between the fluid and porous domain. The resistance to airflow generated by the individual fruit bins was modelled by the Darcy-Forchheimer equation which correlates the pressure drop across the bin with the superficial velocity of the air through the bin. The linear and quadratic coefficients were obtained from detailed discrete element CFD simulations of the airflow and pressure drop across a single wooden bin filled with apple fruit (Ambaw et al., 2013b).

The shear stress transport $k$ - $\omega$ turbulence model (SST $k-\omega$ model) was used in combination with standard wall functions to model turbulence both inside and outside the porous medium (Defraeye et al., 2013; Launder and Spalding, 1974). The turbulence developing inside the porous medium was treated as if the solid phase had no effect on the turbulence generation or dissipation rates. This assumption holds true when the permeability of the medium is quite large and the geometric scale of the solid phase does not interact with the scale of the turbulent eddies (Ansys, 2016), which is the case 
here. In the model, recommended optimal CA storage conditions for the long-term storage of 'Jonagold' apples were assumed ( $1 \% \mathrm{O}_{2}$ and $3 \% \mathrm{CO}_{2}$; Gwanpua et al., 2014a). The thermo-physical properties of air and apples were considered to be constant within the narrow temperature range of the different cooling strategies. For the apples and the air, the thermal conductivity, density and specific heat capacity were 0.580 and $0.024 \mathrm{~W}\left(\mathrm{~m}^{\circ} \mathrm{C}\right)^{-1}, 898.00$ and $1.28 \mathrm{~kg} \mathrm{~m}^{-3}$ and 3780.0 and $1004.4 \mathrm{~J}\left(\mathrm{~kg}^{\circ} \mathrm{C}\right)^{-1}$, respectively (Delele et al., 2012; Laguerre et al., 2015). The heat of respiration generated by the produce was calculated from correlations that relate the temperature of the produce to its rate of carbon dioxide production and subsequently to the heat generation rate $\left(470 \mathrm{~kJ}\left(\mathrm{~mol} \mathrm{CO}_{2}\right)^{-1}\right.$; Hertog et al., 1998; Ho et al., 2013). A non-thermal equilibrium model was used to simulate the heat transfer between the air and the apple fruit. Therefore, two separate volume-averaged heat transport equations for the two phases within the porous medium were solved. Nusselt number correlations were used to calculate the overall heat transfer coefficient between the apples and the air (Nield and Bejan, 2013). The removal of latent heat due to moisture evaporation at the surface of the fruit was not taken into account. Furthermore, it was assumed that buoyancy and radiation effects were negligible and that the heat transfer between the cold air and the warmer produce would not have an effect on the surrounding fluid flow (Opara, 2011).

The cooling unit was implemented with a velocity and a time-dependent temperature boundary condition (see 2.3) at the outlet of the cooling unit and a conservation of mass flow at the side of the fans. The total refresh rate of the entire air volume was about 90 times per hour which corresponds to a fixed inlet boundary condition of $3.2 \mathrm{~m} \mathrm{~s}^{-1}$, representing a continuous air recirculation in the coolstore. The boundaries of the room and the other surfaces of the cooling unit were modelled as adiabatic no-slip walls. Heat influx through the floor, walls, ceiling and door is included in the model by applying a heat flux term on these boundaries with an outside temperature of $10.5^{\circ} \mathrm{C}$. The initial temperature of the apples and the air was assumed $1.5^{\circ} \mathrm{C}$ and $0.0^{\circ} \mathrm{C}$, respectively.

\subsection{Model of the temperature control with different differential ranges}

The temperature sensor located under the cooling unit was also modelled and its reading was used to control the on/off switching of the cooling unit. If the temperature reading was above a set upper threshold cooling was started; if it reached the lower threshold (upper threshold minus the differential), cooling was stopped. During each phase, there was a continuous air recirculation in the room.

Three different cooling differentials $\left(0.40,0.50,0.70{ }^{\circ} \mathrm{C}\right)$ around a fixed setpoint temperature $(0.95$ ${ }^{\circ} \mathrm{C}$ ) were considered. Thus in scenario 1 , the upper threshold was $1.15^{\circ} \mathrm{C}$, and the lower threshold 0.75 ${ }^{\circ} \mathrm{C}$. For the other two scenarios, the upper/lower thresholds were $1.20 / 0.70{ }^{\circ} \mathrm{C}$ and $1.30 / 0.60{ }^{\circ} \mathrm{C}$, 
respectively.

During the "on" phase of the cooling cycle (i.e. when the upper limit of the temperature differential was reached), the evaporator outlet air temperature was set to $0{ }^{\circ} \mathrm{C}$. During the "off" phase (i.e. when the lower limit of the temperature differential was reached), the evaporator air temperature gradually increased over time when active cooling stopped but air continued to be cooled by flowing over the evaporator tubes. This was calculated with a lumped heat transfer model of the tubular heat exchanger inside the cooling unit (Delele et al., 2009; Nahor et al., 2005; Thulukkanam, 2013) and was based on Eq. 1:

$$
\begin{aligned}
& \rho_{a} q_{a} C_{p, a}\left(T_{a}-T_{i}\right)=h_{c} A_{c}\left(T_{c}-T_{a}\right) \\
& m_{c} C_{p, c} \frac{\partial T_{c}}{\partial t}=h_{c} A_{c}\left(T_{a}-T_{c}\right)
\end{aligned}
$$

where $\rho_{a}$ is the density of the air, $C_{p, a}$ the specific heat capacity of the air, $q_{a}$ is the volume airflow rate through the evaporator $\left(11.25 \mathrm{~m}^{3} \mathrm{~s}^{-1}\right), T_{a}(\mathrm{~K})$ the evaporator outlet air temperature, $T_{i}(\mathrm{~K})$ the evaporator inlet air temperature (assumed equal to the controller temperature), $A_{c}$ the heat transfer area of the tubes $\left(165 \mathrm{~m}^{2}\right), m_{c}$ their mass $(821 \mathrm{~kg}), C_{p, c}$ the specific heat capacity $\left(910 \mathrm{~J} \mathrm{~kg}^{-1}{ }^{\circ} \mathrm{C}^{-1}\right)$ and $T_{c}(\mathrm{~K})$ the temperature of the evaporator tubes. The air side heat transfer coefficient of the cooling unit $\left(h_{c}, \mathrm{~W} \mathrm{~m}^{-}\right.$ ${ }^{2} \mathrm{~K}^{-1}$ ) was represented by the Colburn ja factor (Bejan, 1993; Tso et al., 2006). Figure 3 shows the experimental results obtained from Ambaw et al. (2016) of the air temperature dynamics of the tubular heat exchanger during the "off" phase of the cooling cycle. Since the initial temperature of $T_{c}$ was not known a best fit was used, and the inlet air temperature during the "off" phase of the cooling cycle was approximated with an exponential curve which corresponds well with the experimental results and model (1). A more detailed model of the cooling unit can also be implemented at the cost of additional equations and parameters (Nahor et al., 2004). The simplified lumped model of the tubular heat exchanger was implemented in ANSYS CFX 17.2 with a Fortran subroutine.

\subsection{Quality assessment using the FRISBEE tool}

The FRISBEE tool developed by Gwanpua et al. (2014b) allows the evolution of several quality attributes of fresh horticultural produce along the postharvest cold chain. With the FRISBEE tool, quality assessment is achieved with kinetic models that accurately describe and predict the processes that cause product deterioration such as loss of firmness due to the breakdown of pectin (Gwanpua et al., 2013), colour change due to the breakdown of skin chlorophyll pigments (Gwanpua et al., 2014c), etc. The rate constants of these degradation kinetic models are assumed to depend on temperature according to the Arrhenius equation. In this study, the FRISBEE tool was used to evaluate the effect of adaptive on-off cooling regimes on the final quality of apple fruit after long-term storage (i.e. the 
apple firmness). The simulated product temperature histories of the three cooling strategies were imported in the FRISBEE tool to calculate the changes of firmness of the apple fruit in function of storage time (Gwanpua et al., 2013). Here, the apples were given a typical initial firmness of $81 \mathrm{~N}$, representing the average of freshly picked fruit at optimal harvest date.

\subsection{Solution procedure}

The transport equations of the model were solved using the finite volume technique of ANSYSCFX 15.0. Both the air and porous domains were discretized using tetrahedral and hexahedral mesh elements, respectively. A mesh sensitivity analysis was performed with the Richardson extrapolation to calculate the average discretization error in terms of mass and heat fluxes across several selected faces of the porous medium (Celik et al., 2008; Franke et al., 2007). With a total of 2.51 million mesh elements for the entire computational domain, discretization errors were maximally $5 \%$. Based on a temporal sensitivity analysis, all transient simulations were run for $35 \mathrm{~h}$, with a time step during the on- and off-cooling phase of $30 \mathrm{~s}$ and $300 \mathrm{~s}$, respectively with 15 iterations selected as the optimum trade-off between improved accuracy and computational time requirement. The advection and transient schemes used the high-resolution spatial differencing method and second-order backward Euler method, respectively. The calculation time of the simulations was reduced by solving the mass and momentum equations decoupled from the heat transfer equations. First, a steady state fluid flow calculation was performed after which a converged solution for the airflow was obtained. Next, the converged solution is used as initial values for solving the unsteady heat transfer equations. All calculations were performed on a 64-bit Intel ${ }^{\circledR}$ Xeon ${ }^{\circledR}$ CPU E5-2630, $2.30 \mathrm{GHz}, 64$ GB RAM, Windows $7 \mathrm{PC}$ and took more than $150 \mathrm{~h}$ to complete.

\section{Results}

\subsection{Airflow pattern}

Figure 4 shows the airflow inside the coolstore. Near the exit of the cooling unit the average velocity is $3 \mathrm{~m} \mathrm{~s}^{-1}$ and the air flows over the top bins towards the door. The airflow does not attach to the ceiling, but soon falls down on the top bins. A part of the airflow returns to take a shortcut via the top bins underneath the cooling unit back to the fans, while a small backward swirl attaches to the ceiling. The other part of the air is deflected upwards by a large swirl that persists in the free space on top of the last column of bins at the wall opposite to the cooling unit. The air then penetrates the stack of fruit bins at a low velocity of $1.07 \pm 0.60 \mathrm{~m} \mathrm{~s}^{-1}$. In general, the velocity through the stack gradually increases when the air flows back towards the cooling unit (along the z-axis) and from the bottom to the top (along the y-axis). Finally, the returning airflow is drawn back in to the cooling unit by the fans, 
creating a zone of relatively high air velocity near the wall under the cooling unit.

\subsection{Temperature distribution}

Temperature contour plots in the middle of the coolstore at the end of each phase in the cooling cycle for the three cooling scenarios are presented in Figure 5. Independent of the applied temperature differential range, a warmer zone develops underneath the cooling unit and in the middle of the stack while the outer edges of the stack are at lower temperatures. Indeed, the outer edges are exposed to high air velocity while the airflow drastically slows down once it enters the stack. Then, the cold air takes up heat from the produce, thereby increasing temperature. A warmer zone consequently develops in the inner part of the stack. Although the air velocity underneath the cooling unit increases, the warmer air from the inner parts of the stack is drawn upwards and causes the warmer zone to spread also towards the top bins.

By implementing a larger temperature differential range, the duration of the on and off cooling periods increases, because it takes longer to reach the thresholds. During the "on" phase, the edges of the stack are, therefore, exposed to the cold air for a longer period of time, leading to lower temperatures. The opposite effect is true during the "off" phase where the controller will take longer to react to the higher upper temperature threshold. As a result, at the end of the "off" phase (Figure 4b), the average product temperature, but also the degree in temperature uniformity is higher in the case of a higher differential. This higher degree in uniformity however disappears again during the "on" phase of the cooling process.

\subsection{Temperature dynamics of the apple fruit}

The temperature dynamics of the produce at four distinct positions in the coolstore during the different cooling strategies are presented in Figure 6. The fruit bins located in the top part and on the outer edges of the stack (bin 1 and 2) were exposed to the incoming cold air and followed the applied cooling regime. The centre part and the zone under the cooling unit however, varied little over time. With a higher cooling differential, the temperature fluctuations were more pronounced throughout the stack. Note that at the peak temperature, the temperature in the room is more uniform for the higher differential range, while at the lowest temperature the uniformity is lower. Thus, the off-time of the cooler, with continued air circulation, can be used beneficially to achieve a more homogeneous temperature by distributing the heat across the room.

A summary of the different cooling scenarios is presented in Table 1. In each of the three situations, the product temperature in the coolstore was on average $1.0{ }^{\circ} \mathrm{C}$, or equal to the optimal storage temperature for 'Jonagold' apples. The $0.4{ }^{\circ} \mathrm{C}$ temperature differential resulted in short cooling times 
(15 min) with relatively long periods between successive cooling actions (400 min). Increasing the cooling differential, however, required an exponentially increasing cooling time $\left(180 \mathrm{~min}\right.$ at $\left.0.7^{\circ} \mathrm{C}\right)$. Reaching the lower temperature thresholds takes longer because the difference between the cooling air temperature and the lower thresholds becomes quite small. One possibility to reduce the cooling time needed in the "on" phase is implementing a lower air temperature at the risk of inducing chilling injury.

\subsection{Net energy expenditure of cooling}

The net energy expenditure used during the "on" phase of several consecutive cooling actions is calculated as the integral of the mass flow rate times temperature differences multiplied by the specific heat capacity of air between the inlet and outlet of the cooling unit and is depicted in Figure 7. It can be observed that implementing a high temperature differential $\left(0.7{ }^{\circ} \mathrm{C}\right)$ during long-term storage of produce consumes a considerably larger amount of energy than smaller temperature differentials $(0.4$ ${ }^{\circ} \mathrm{C}$ or $0.5^{\circ} \mathrm{C}$ ). The energy consumption increases exponentially with the value of the differential range. It should be noted that a continuous airflow was used in this study. By allowing the air ventilator fans to stop working, it is possible to reduce the energy consumption as was pointed out by East et al. (2013) and Ambaw et al. (2016).

\subsection{Evaluation of product quality with the FRISBEE tool}

Figure 8 depicts the evolution of the firmness quality of the apples at four distinct locations. Over time, the apple firmness decreased until the flesh firmness fell below the critical quality limit for consumer approval ( $\sim 50 \mathrm{~N}$; Hertog et al., 2001; Johnston et al., 2001). After 180 to $200 \mathrm{~d}$, all apples reached the lower quality limit which agreed well with the experimental results obtained by Gwanpua et al. (2013). Throughout the stack, however, a distinct product quality heterogeneity can be observed. The location in the stack clearly influenced the final product quality. During storage, the apples located in the warmer zones (bins 3 and 4) were exposed to a higher average temperature and, thus, reached the quality limit first. The apples located in the top region of the stack (bin 2) were directly exposed to the air supply and had the lowest average product temperatures. Consequently, the quality limit was reached two weeks later than in bin 3 and 4. The applied cooling differential did not have a significant effect on final product firmness, an observation also noted by East et al. (2013). Rather, the temperature heterogeneity caused by the airflow through the stacking pattern appears to be of more concern regarding fruit quality. Although firmness is one of the main quality parameters, background colour change during storage is even more influenced by the exposed temperatures during the CA storage (Duret et al., 2014). The combination of these two parameters would thus identify an even larger quality heterogeneity throughout the cool room due to the combination of the airflow and the applied 
temperature differentials.

\section{Discussion}

\subsection{Practical implementation and industrial validation}

The results were discussed with a group of refrigeration specialists and coolstore managers in Flanders. This group indicated to have similar practical experiences as the results obtained from this study. Coolstore managers concluded that small temperature differentials $\left(0.3\right.$ to $\left.0.5^{\circ} \mathrm{C}\right)$ used today in coolstores are optimal for reducing energy consumptions and they are not eager to explore other settings. Aspects such as airflow distribution affected by room and stacking design are considered much more relevant for improving temperature uniformity (Ambaw et al., 2016; Delele et al., 2012, 2009). For industrial relevance purposes of the present study, reference is given to results of an experimental trial of temperature fluctuation measurements in a CA coolstore filled with 126 tons (305 wooden bins) of 'Jonagold' apples (Veiling Haspengouw, Sint-Truiden, Belgium) operated at $0.8{ }^{\circ} \mathrm{C}$ with a differential of $0.3{ }^{\circ} \mathrm{C}$ (data not shown). Here, fluctuations were $0.3^{\circ} \mathrm{C}$ (st. dev.) in the supply air region, while it was only $0.1{ }^{\circ} \mathrm{C}$ in the bulk of the bins. This complies with the results found here.

\subsection{Effect of different cooling systems}

In this study a simplified lumped model of the tubular heat exchanger was used. The parameters for the exponential approximation were obtained from a best-fit approach on experimental data. The approximation procedure discussed in this work can also be used to model the temperature dynamics of different cooling systems if empirical data is available. If not, more advanced models to describe the different operations in the cooling system are available (Ding, 2007; Eames et al., 2012; Hoang et al., 2015; Nahor et al., 2004).

\section{Conclusions}

This study evaluated an adaptive on-off cooling strategy based on modelling different temperature differentials. Increasing the differential around a setpoint temperature causes larger product timetemperature fluctuations, and consumes more energy that increases exponentially with increasing differentials. Although no effects on apple firmness of the larger differentials were observed, using a large cooling differential during long-term storage of apples thus appears not to be an appropriate strategy to reduce energy. Lowering the evaporator outlet air temperature to lower values than $0{ }^{\circ} \mathrm{C}$ could reduce the cooling times and thus also the energy consumption, at the risk of chilling injury. In the storage room, a "hot" zone develops in the middle of the stack and underneath the cooling unit where the product temperature remains higher and rather constant in comparison to the outer regions of the stack that respond quickly to a change in supply air temperature. This resulted in a spatial 
difference in the final quality of the apples throughout the coolstore. Solving the continued spatial temperature heterogeneity will be more beneficial for better quality preservation and reducing energy costs. To this end, alternative airflow designs should be developed and investigated for which this model can be employed.

\section{Acknowledgements}

The financial support of the Flanders Innovation \& Entrepreneurship (project VLAIO 120745) and collaborations with Verbond van Belgische Tuinbouwcoöperaties, Vos Technics, ABCool, HVA koeling, Aucxis Trading Solutions and Agrofresh are greatly acknowledged.

\section{References}

Ambaw, A., Bessemans, N., Gruyters, W., Gwanpua, S.G., Schenk, A., De Roeck, A., Delele, M.A., Verboven, P., Nicolai, B.M., 2016. Analysis of the spatiotemporal temperature fluctuations inside an apple cool store in response to energy use concerns. Int. J. Refrig. 66, 156-168. doi:10.1016/j.ijrefrig.2016.02.004

Ambaw, A., Delele, M.A., Defraeye, T., Ho, Q.T., Opara, U.L., Nicolaï, B.M., Verboven, P., $2013 a$. The use of CFD to characterize and design post-harvest storage facilities: Past, present and future. Comput. Electron. Agric. 93, 184-194. doi:10.1016/j.compag.2012.05.009

Ambaw, A., Verboven, P., Delele, M.A., Defraeye, T., Tijskens, E., Schenk, A., Verlinden, B.E., Opara, U.L., Nicolai, B.M., 2013b. CFD-Based Analysis of 1-MCP Distribution in Commercial Cool Store Rooms: Porous Medium Model Application. Food Bioprocess Technol. 7, 1903-1916. doi:10.1007/s11947-013-1190-9

Ansys, 2016. ANSYS FLUENT 17.2 Users Guide: 6.2.3.4. Treatment of the energy equation in porous media., ANSYS, Inc., Canonsburg, PA.

ASHRAE, 2006. ASHRAE Handbook: Refrigeration, SI edition. ed. American Society of Heating, Refrigerating and Air-Conditioning Engineers, Atlanta.

ASHRAE, 2010. ASHRAE Handbook: Refrigeration, SI Edition. ed. American Society of Heating, Refrigerating and Air-Conditioning Engineers, Atlanta.

Bejan, A., 1993. Heat Transfer. Jonn Wiley \& Sons, Inc., New York.

Blazek, J., 2015. Computational fluid dynamics: Principles and applications, Third. ed. Oxford, UK.

Celik, I.B., Ghia, U., Roache, P.J., Freitas, C.J., 2008. Procedure for estimation and reporting of uncertainty due to discretization in CFD applications. J. Fluids Eng.

Defraeye, T., Verboven, P., Nicolai, B., 2013. CFD modelling of flow and scalar exchange of spherical food products: Turbulence and boundary-layer modelling. J. Food Eng. 114, 495-504. doi:10.1016/j.jfoodeng.2012.09.003

Defraeye, T., Verboven, P., Opara, U.L., Nicolai, B.M., Cronjé, P., 2015. Feasibility of ambient loading of citrus fruit into refrigerated containers for cooling during marine transport. Biosyst. Eng. 134, 20-30. doi:10.1016/j.biosystemseng.2015.03.012

Delele, M.A., Schenk, A., Tijskens, E., Ramon, H., Nicolaï, B.M., Verboven, P., 2009. Optimization of the humidification of cold stores by pressurized water atomizers based on a multiscale CFD model. J. Food Eng. 91, 228-239. doi:10.1016/j.jfoodeng.2008.08.027

Delele, M.A., Vorstermans, B., Creemers, P., Tsige, A.A., Tijskens, E., Schenk, A., Opara, L., Nicolaï, 
B.M., Verboven, P., 2012. CFD model development and validation of a thermonebulisation fungicide fogging system for postharvest storage of fruit. J. Food Eng. 108, 59-68. doi:10.1016/j.jfoodeng.2011.07.030

Ding, G., 2007. Recent developments in simulation techniques for vapour-compression refrigeration systems. Int. J. Refrig. 30, 1119-1133. doi:10.1016/j.ijrefrig.2007.02.001

Duret, S., Gwanpua, S.G., Hoang, H.M., Guillier, L., Flick, D., Laguerre, O., Verlinden, B.E., De Roeck, A., Nicolai, B.M., Geeraerd, A., 2014. Identification of the significant factors in food quality using global sensitivity analysis and the accept-and-reject algorithm. Part III: Application to the apple cold chain. J. Food Eng. 148, 66-73. doi:10.1016/j.jfoodeng.2014.09.039

Eames, I.W., Brown, T., Evans, J.A., Maidment, G.G., 2012. Description and validation of a computer based refrigeration system simulator. Comput. Electron. Agric. 85, 53-63. doi:10.1016/j.compag.2012.03.010

East, A.R., Smale, N.J., Trujillo, F.J., 2013. Potential for energy cost savings by utilising alternative temperature control strategies for controlled atmosphere stored apples. Int. J. Refrig. 36, 11091117. doi:10.1016/j.ijrefrig.2012.10.028

Franke, J., Hellsten, A., Schlünzen, H., Carissimo, B., 2007. Best practice guidelines for the CFD simulation of flows in the urban environment. COST Action 732 Qual. Assur. Improv. microscale Meteorol. Model. Hamburg, Ger.

Gwanpua, S.G., Van Buggenhout, S., Verlinden, B.E., Christiaens, S., Shpigelman, A., Vicent, V., Kermani, Z.J., Nicolai, B.M., Hendrickx, M., Geeraerd, A., 2014a. Pectin modifications and the role of pectin-degrading enzymes during postharvest softening of Jonagold apples. Food Chem. 158, 283-291. doi:10.1016/j.foodchem.2014.02.138

Gwanpua, S.G., Verboven, P., Leducq, D., Brown, T., Verlinden, B.E., Bekele, E., Aregawi, W., Evans, J., Foster, a., Duret, S., Hoang, H.M., van der Sluis, S., Wissink, E., Hendriksen, L.J. a M., Taoukis, P., Gogou, E., Stahl, V., El Jabri, M., Le Page, J.F., Claussen, I., Indergård, E., Nicolai, B.M., Alvarez, G., Geeraerd, a. H., 2014b. The FRISBEE tool, a software for optimising the trade-off between food quality, energy use, and global warming impact of cold chains. J. Food Eng. 148, 2-12. doi:10.1016/j.jfoodeng.2014.06.021

Gwanpua, S.G., Verlinden, B.E., Hertog, M.L.A.T.M., Van Impe, J., Nicolai, B.M., Geeraerd, A.H., 2013. Towards flexible management of postharvest variation in fruit firmness of three apple cultivars. Postharvest Biol. Technol. 85, 18-29. doi:10.1016/j.postharvbio.2013.04.015

Gwanpua, S.G., Vicent, V., Verlinden, B.E., Hertog, M.L.A.T.M., Nicolai, B.M., Geeraerd, A.H., 2014c. Managing biological variation in skin background colour along the postharvest chain of "Jonagold" apples. Postharvest Biol. Technol. 93, 61-71. doi:10.1016/j.postharvbio.2014.02.008

Hertog, M.L.A.T.M., Nicholson, S.E., Banks, N.H., 2001. The effect of modified atmospheres on the rate of firmness change in "Braeburn" apples. Postharvest Biol. Technol. 23, 175-184.

Hertog, M.L.A.T.M., Peppelenbos, H.W., Evelo, R.G., Tijskens, L.M.M., 1998. A dynamic and generic model of gas exchange of respiring produce: the effects of oxygen, carbon dioxide and temperature. Postharvest Biol. Technol. 14, 335-349. doi:10.1016/S0925-5214(98)00058-1

Ho, Q.T., Verboven, P., Verlinden, B.E., Schenk, A., Nicolai, B.M., 2013. Controlled atmosphere storage may lead to local ATP deficiency in apple. Postharvest Biol. Technol. 78, 103-112. doi:10.1016/j.postharvbio.2012.12.014

Hoang, H.M., Duret, S., Flick, D., Laguerre, O., 2015. Preliminary study of airflow and heat transfer in a cold room filled with apple pallets: Comparison between two modelling approaches and 
experimental results. Appl. Therm. Eng. 76, 367-381. doi:10.1016/j.applthermaleng.2014.11.012

Johnston, J.W., Hewett, E.W., Hertog, M.L.A.T.M., Harker, F.R., 2001. Temperature induces differential softening responses in apple cultivars. Postharvest Biol. Technol. 23, 185-196. doi:10.1016/S0925-5214(01)00127-2

Kart, M.C.O., Demircan, V., 2014. An economic comparison of conventional and modern cold storage facities in Turkey. Custos E Agronegocio Line 10, 118-130.

Laguerre, O., Duret, S., Hoang, H.M., Guillier, L., Flick, D., 2015. Simplified heat transfer modeling in a cold room filled with food products. J. Food Eng. 149, 78-86. doi:10.1016/j.jfoodeng.2014.09.023

Launder, B.E., Spalding, D.B., 1974. The numerical computation of turbulent flows. Comput. Methods Appl. Mech. Eng. 3, 269-289. doi:10.1016/0045-7825(74)90029-2

Liu, S., Masliyah, J.H., 2005. Dispersion in porous medium, in: Kambiz, V. (Ed.), Handbook of Porous Medium. Taylor \& Francis Group LLC, pp. 81-135.

McCormick, R., Neuwald, D.A., Streif, J., 2010. A case study: Potential energy savings using 1-MCP with "Gala" apples in commercial CA storage. Acta Hortic. 877, 323-326.

Nahor, H.B., Hoang, M.L., Verboven, P., Baelmans, M., Nicolaï, B.M., 2005. CFD model of the airflow, heat and mass transfer in cool stores. Int. J. Refrig. 28, 368-380. doi:10.1016/j.ijrefrig.2004.08.014

Nahor, H.B., Scheerlinck, N., Verboven, P., Van Impe, J., Nicolai, B.M., 2004. Continuous/discrete simulation of controlled atmosphere (CA) cool storage systems: model development and validation using pilot plant CA cool storage. Int. J. Refrig. 27, 884-894. doi:10.1016/j.ijrefrig.2004.04.011

Nield, D.A., Bejan, A., 2013. Convection in porous media, Fourth. ed. Springer, New York.

Opara, U.L., 2011. From hand holes to vent holes: What is next in innovative horticultural packaging? Inaugural Lecture (p. 24). Stellenbosch University, Stellenbosch, South Africa

Prusky, D., 2011. Reduction of the incidence of postharvest quality losses, and future prospects. Food Secur. 3, 463-474. doi:10.1007/s12571-011-0147-y

Rees, D., Farrell, G., Orchard, J., 2012. Crop Post-Harvest: Science and Technology: Perishables. Blackwell Publishing Ltd., West Sussex, United Kingdom.

Thompson, J.F., Mitchell, F.G., Rumsey, T.R., Kasmire, R.F., Crisosto, C.H., 2008. Commercial cooling of fruits, vegetables, and flowers. University of California, California.

Thulukkanam, K., 2013. Heat exchanger design handbook, Second Edi. ed. CRC Press, Boca Raton.

Tso, C.P., Cheng, Y.C., Lai, A.C.K., 2006. An improved model for predicting performance of finned tube heat exchanger under frosting condition, with frost thickness variation along fin. Appl. Therm. Eng. 26, 111-120. doi:10.1016/j.applthermaleng.2005.04.009

Versteeg, H.K., Malalasekera, W., 2007. An Introduction to Computational Fluid Dynamics, 2nd editio. ed. Pearson Prentice Hall, Harlow, UK. 


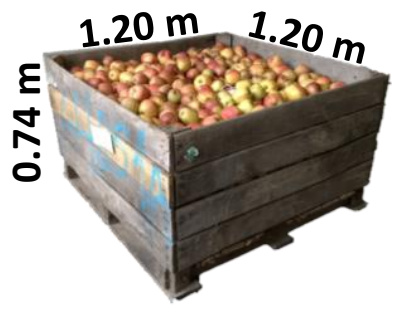

(a)

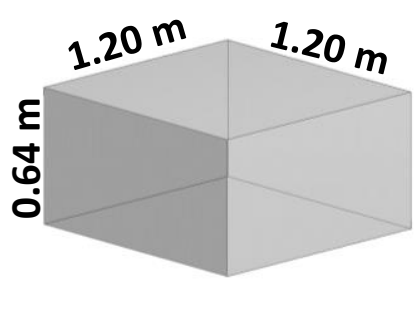

(b)

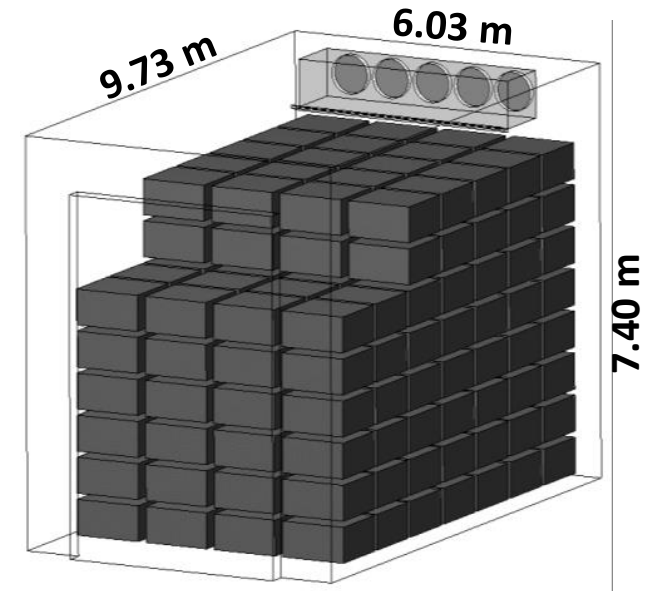

(c)

Figure 1: Schematic representation of the cool store. (a) wooden bin filled with $\sim 380 \mathrm{~kg}$ 'Jonagold' apples; (b) porous medium representation of the wooden fruit bin filled with apple fruits; (c) geometrical representation of the cool store loaded with 208 wooden fruit bins.

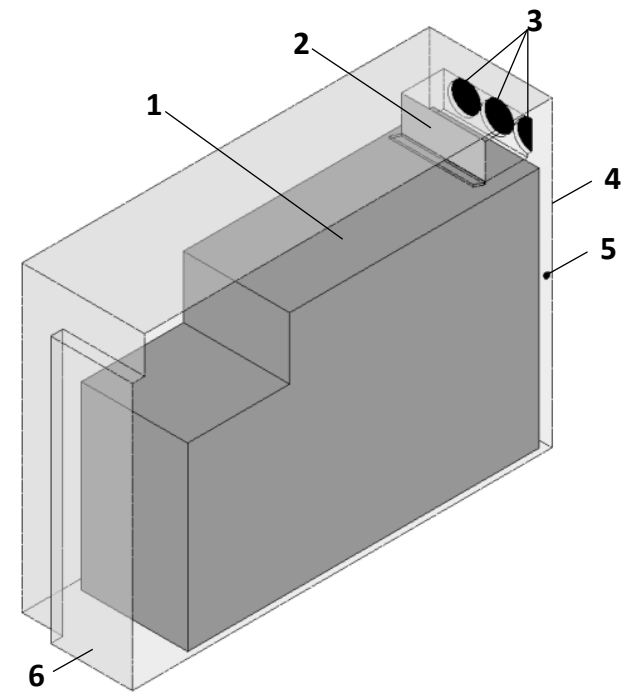

Figure 2: Computational domain representation of the simulated apple cool store: 1) porous medium model of stacked fruit bins filled with apples; 2) outlet of the cooling unit; 3) ventilators of the cooling unit; 4) symmetry plane; 5) position of a thermocouple that controls the on-off cooling cycles of the cooling unit based on designated cooling differentials; 6 ) door of the coolstore. 


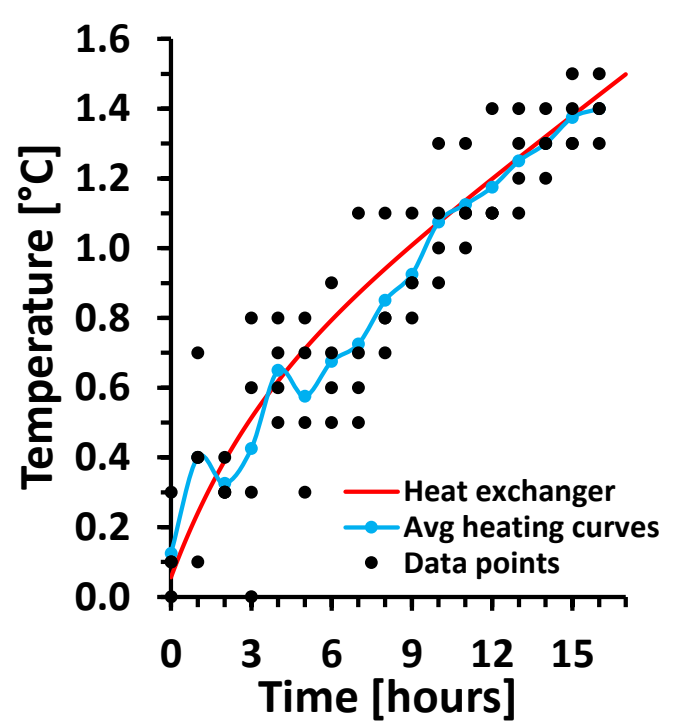

Figure 3: The air temperature dynamics of the tubular heat exchanger during the "off" phase of the cooling cycle, approximated with an exponential curve (red) where the air temperature gradually increases over time; the average "heating curve" during the "off" phase of the cooling cycle (blue) and the data points of the "heating curve" obtained with permission from Ambaw et al. (2016).

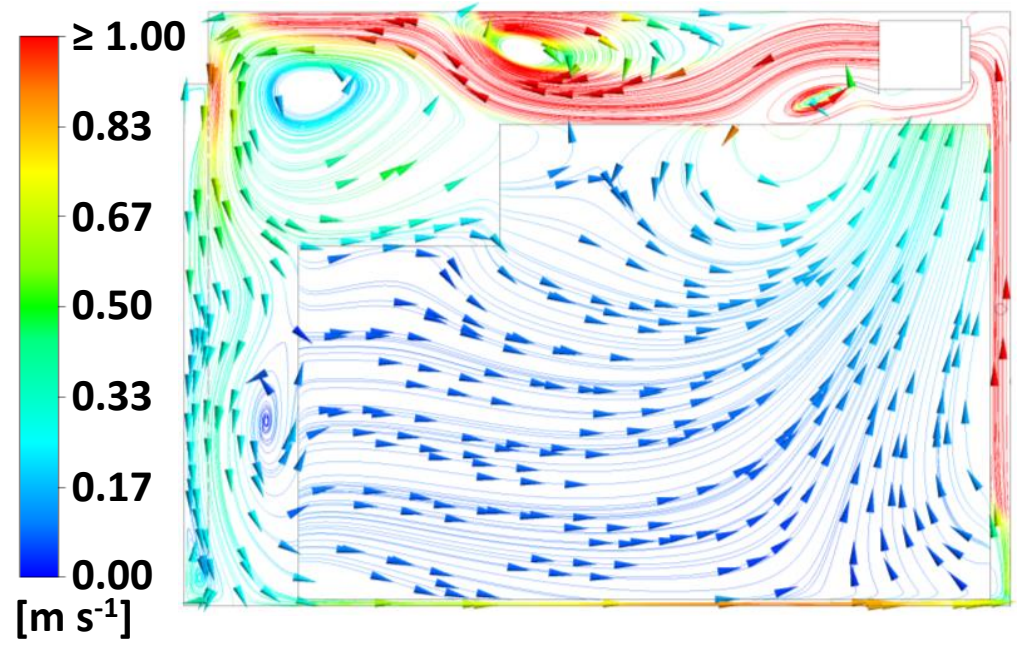

Figure 4: Velocity stream lines showing the airflow pathway in the middle vertical plain of the cool store. The colour bar indicates the magnitude of the local velocities; the arrows show the velocity directions. The cold air enters the air domain with an average velocity of $3.2 \mathrm{~m} \mathrm{~s}^{-1}$ which corresponds to a total refresh rate of the entire air volume of about $90 \mathrm{~h}^{-1}$. 


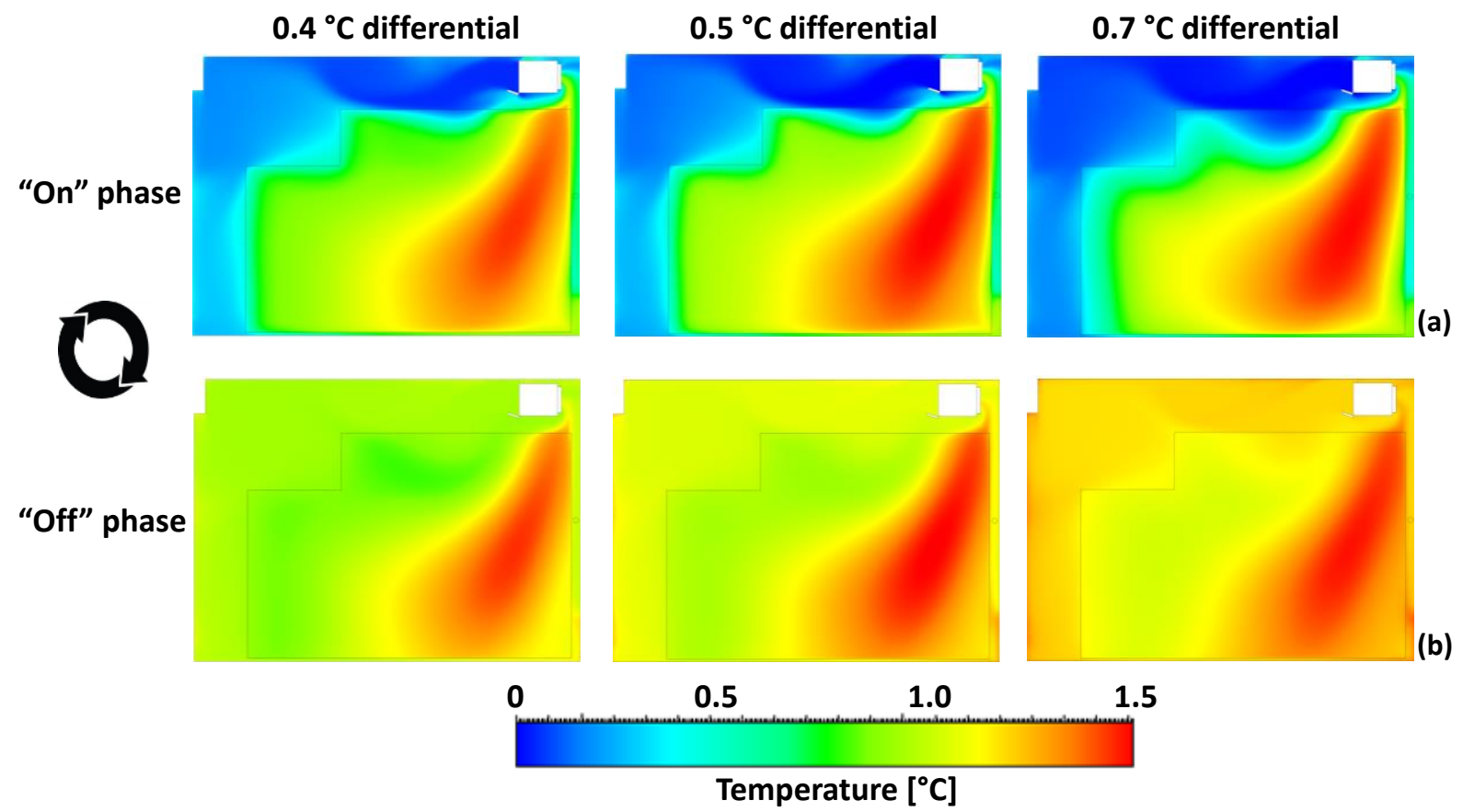

Figure 5: Air/product temperature contour plots (outside/inside the stack) in the middle vertical plain of the cool store for the three different cooling differentials with a) at the end of the "on" phase and b) at the end of the "off" phase. Red colour indicates a warm temperature; blue colour indicates a cold temperature. 

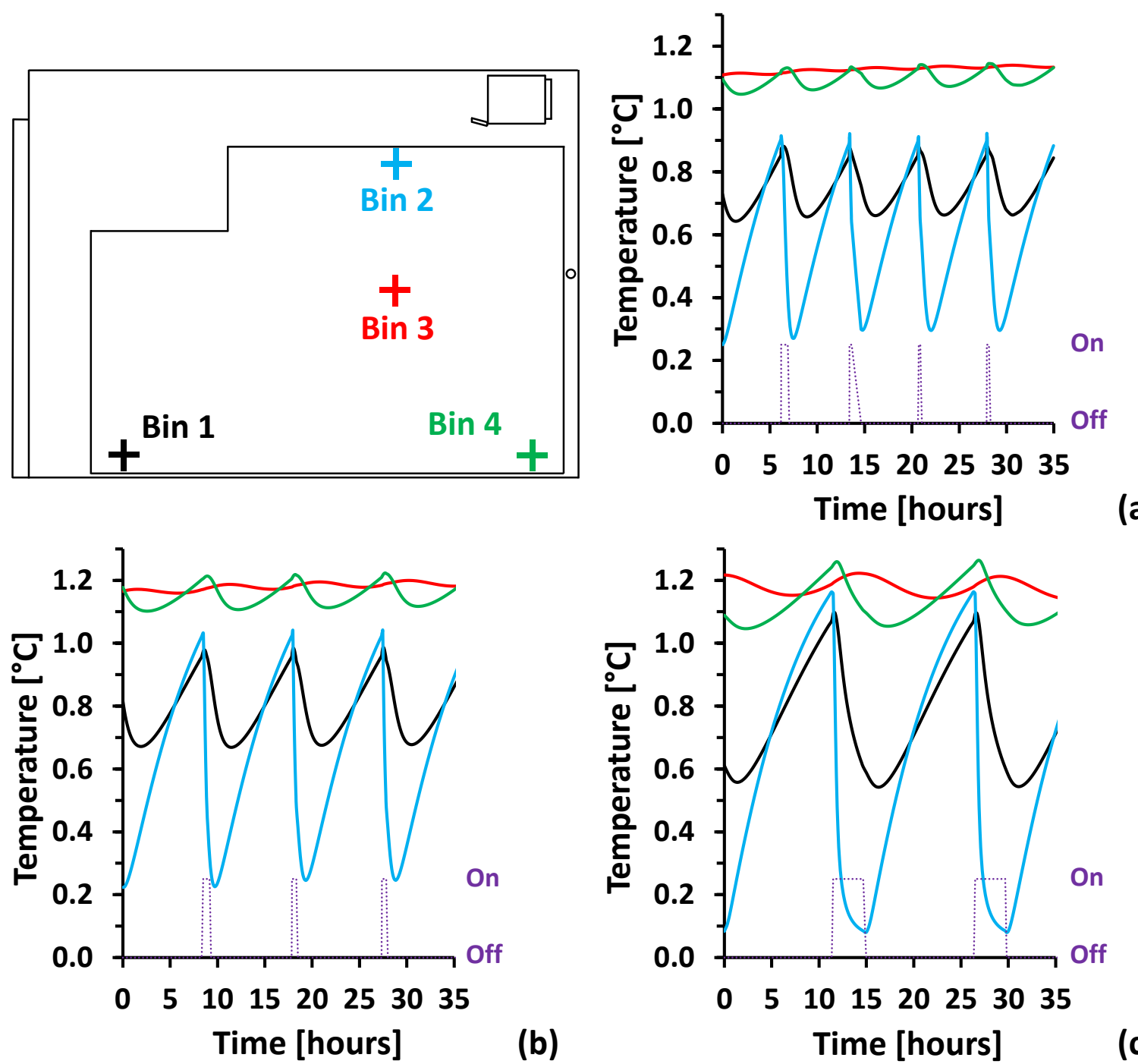

Figure 6: Product temperature profiles calculated over time at distinct locations inside the fruit stack, shown in the cross section of the coolstore, for the three different cooling differentials: a) $0.4{ }^{\circ} \mathrm{C}$; b) $0.5^{\circ} \mathrm{C}$; c) $0.7^{\circ} \mathrm{C}$. The "on""off" cooling phases in the cooling cycles are indicated with the dashed purple lines.

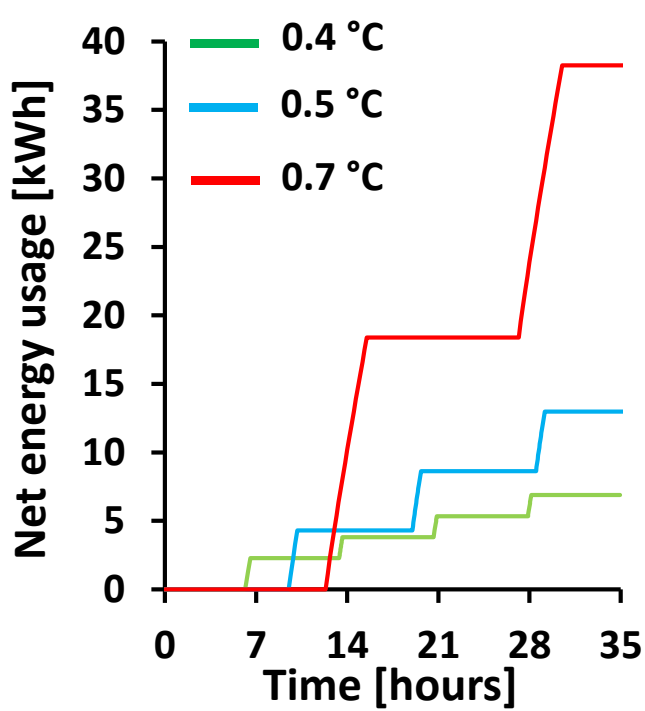

Figure 7: Net energy usage during the "on" phase of several cooling cycles for the three different cooling differentials 

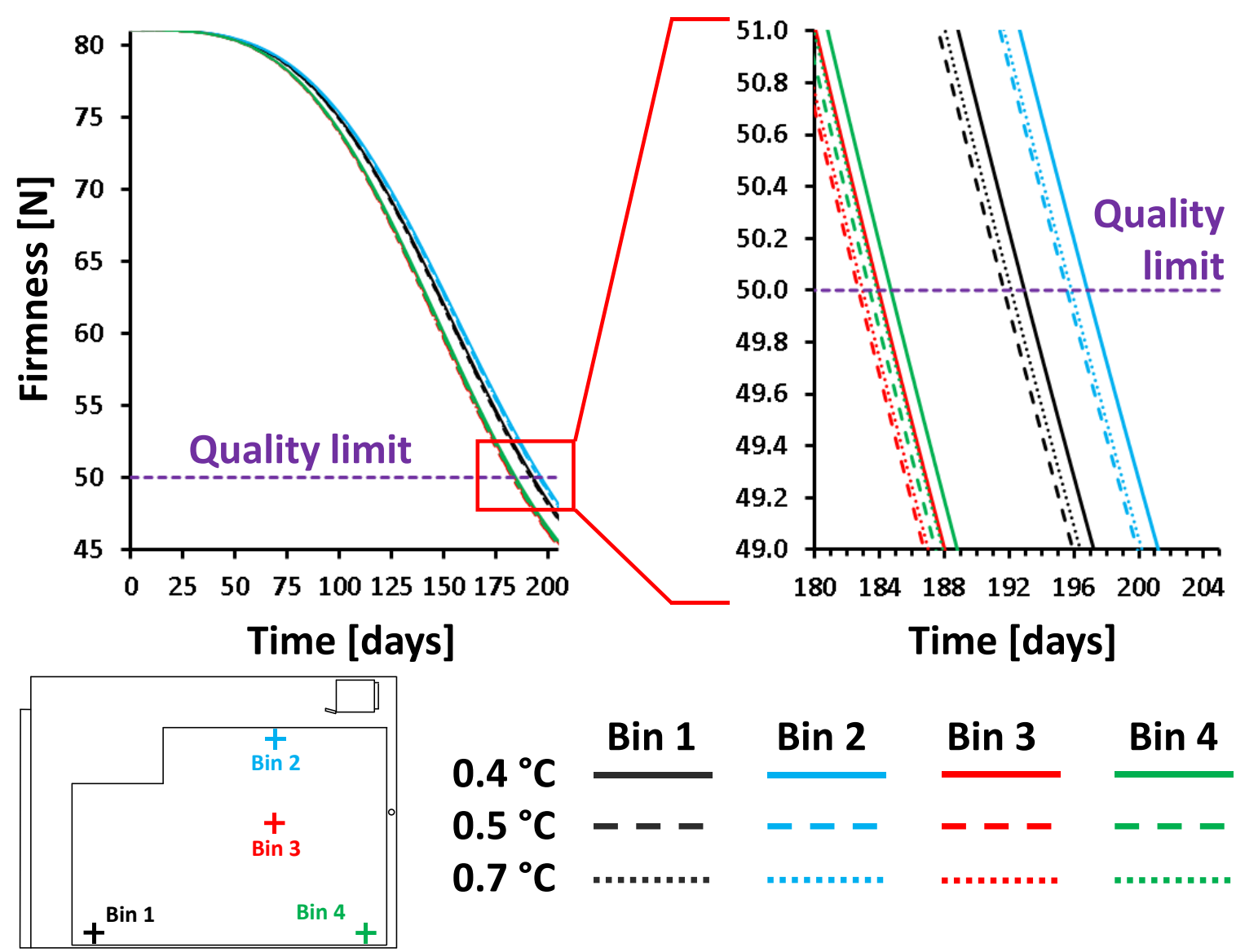

Figure 8: Evolution of the firmness quality of the apples at four distinct locations shown in the cross section of the coolstore. The quality limit of the firmness of apples is $50 \mathrm{~N}$ and is indicated with the dashed purple line.

Table 1. Summary of the simulated cases

\begin{tabular}{|c|c|c|c|}
\hline & \multicolumn{3}{|c|}{ Temperature differential range } \\
\hline & $0.4^{\circ} \mathrm{C}$ & $0.5^{\circ} \mathrm{C}$ & $0.7^{\circ} \mathrm{C}$ \\
\hline $\mathbf{T}_{\text {room,ave }}\left[{ }^{\circ} \mathbf{C}\right]$ & 0.6 & 0.7 & 0.6 \\
\hline $\mathbf{T}_{\text {product,ave }}\left[{ }^{\circ} \mathbf{C}\right]$ & 1.0 & 1.0 & 1.0 \\
\hline On-cooling time [min] & 15 & 30 & 180 \\
\hline Off-cooling time [min] & 400 & 530 & 710 \\
\hline \# min. per day “on" phase & 52 & 77 & 291 \\
\hline
\end{tabular}

